\title{
Histórias Fantásticas: produção de textos com suporte digital na Educação Infantil
}

\author{
Maria Auricélia da Silva ${ }^{1}$, José Aloísio Macedo Filho ${ }^{2}$, José Aires de Castro Filho ${ }^{3}$ \\ ${ }^{1}$ Unidade Universitária Federal de Educação Infantil Núcleo de Desenvolvimento da \\ Criança - Universidade Federal do Ceará (UFC) - Campus do Pici - Bloco 859 - \\ Fortaleza-CE \\ ${ }^{2}$ Faculdade de Educação - Universidade Federal do Ceará (UFC) - Campus do Pici - \\ Rua Waldery Uchôa, 01 - Benfica, Fortaleza - CE, 60020-060 - Fortaleza-CE \\ ${ }^{3}$ Instituto UFC Virtual - Universidade Federal do Ceará (UFC) - Campus do Pici - \\ Bloco $9011^{\circ}$ andar, Fortaleza-CE \\ silvauricelia@gmail.com, aloisio.macedo@hotmail.com, \\ aires@irtual.ufc.br
}

\begin{abstract}
This article describes a study carried out with children of five years of age in a process of producing stories with digital support. The objectives of this work were: to accompany the textual production with the use of a digital resource in Early Childhood Education; to verify if/how the use of a digital resource favors the production of stories in Early Children. The qualitative approach of interpretative character was adopted for the follow up of the work and the analysis of the data collected. The results indicated that the use of a digital resource favored the production of stories in Early Childhood Education, as it provided the setting of scenarios, which served as a support for the production of texts by children.
\end{abstract}

Resumo. Este artigo descreve um estudo realizado com crianças de cinco anos de idade em um processo de produção de histórias com suporte digital. Os objetivos deste trabalho consistiram em: acompanhar a produção textual com uso de um recurso digital na Educação Infantil; verificar se/como a utilização de um recurso digital favorece a produção de histórias na Educação Infantil. A abordagem qualitativa de caráter interpretativo foi adotada para o acompanhamento do trabalho e a análise dos dados coletados. Os resultados indicaram que a utilização de um recurso digital favoreceu a produção de histórias na Educação Infantil, pois proporcionou a montagem de cenários, os quais serviram de suporte para a produção de textos pelas crianças.

\section{Introdução}

As crianças, desde a mais tenra idade, entram em contato com recursos tecnológicos diversos, pois nasceram na era digital e, consequentemente, desenvolvem grande familiaridade com tais equipamentos. Desse modo, a Educação Infantil, primeira etapa da Educação Básica, deve oferecer condições favoráveis ao uso de tecnologias digitais para que as crianças ampliem suas experiências. 
Ao discutir as relações que se estabelecem entre as pessoas e as tecnologias, Kenski (2007 p. 21) afirma que "o homem transita culturalmente mediado pelas tecnologias que lhe são contemporâneas. Elas transformam sua maneira de pensar, sentir e agir". Sendo assim, facilmente as crianças utilizam smartphones, tablets, laptops e outros recursos presentes em seu cotidiano.

Convém que as propostas de utilização das Tecnologias Digitais de Informação e Comunicação (TDIC) sejam realizadas conforme as orientações contidas nas Diretrizes Curriculares Nacionais para a Educação Infantil (DCNEI), as quais recomendam a realização de atividades que "possibilitem a utilização de gravadores, projetores, computadores, máquinas fotográficas e outros recursos tecnológicos e midiáticos" [Brasil 2010 p. 27]. Tal recomendação deve ser observada, com atenção especial aos aspectos lúdicos e às interações entre as crianças, entre estas e os professores e no contato com os recursos tecnológicos, utilizados como apoio pedagógico.

As práticas pedagógicas desenvolvidas devem dar atenção especial às interações e às brincadeiras, eixos norteadores do trabalho na Educação Infantil, estabelecidos para garantir a vivência de amplas experiências propostas nas DCNEI [Brasil 2010].

Outro aspecto recomendado desde a Educação Infantil é o convívio com diferentes portadores de texto, nos mais diversos gêneros. As DCNEI orientam que as atividades propostas "possibilitem às crianças experiências de narrativas, de apreciação e interação com a linguagem oral e escrita, e convívio com diferentes suportes e gêneros textuais orais e escritos" [Brasil 2010 p. 25]. Nesse sentido, a produção de narrativas com suporte digital é uma prática adequada para a Educação Infantil.

A despeito de as crianças de até cinco anos, comumente não lerem nem escreverem de forma convencional, são capazes de produzir textos, tendo os professores como escribas. Girão e Brandão (2011) enfatizam que o fato de as crianças ainda não saberem escrever seus textos não significa que não sejam capazes de produzi-los. $O$ registro das ideias das crianças pode ser feito por um escriba ou por ela mesma, conforme os conhecimentos de que já disponha no momento da produção de suas ideias.

Como recomenda o Referencial Curricular para a Educação Infantil [Brasil 1998 p. 146], "é em atividades desse tipo que elas começam a participar de um processo de produção de texto escrito, construindo conhecimento sobre linguagem antes mesmo que saibam escrever autonomamente". A despeito de haver decorrido um período de tempo considerável desde que esse documento foi produzido e divulgado, essa orientação continua atual porque as crianças vivem em um mundo letrado, por conseguinte apropriam-se facilmente do código escrito e têm acesso a diversos portadores de texto em seu cotidiano.

Os Indicadores de Qualidade na Educação Infantil [Brasil 2009] fazem referência à produção de textos como um dos índices de qualidade no trabalho pedagógico desenvolvido com crianças desse nível de escolaridade. O referido documento faz referência à "multiplicidade de experiências e linguagens" a partir das quais é possível observar se "as crianças são incentivadas a produzir textos mesmo sem saber ler e escrever" [Brasil 2009 p. 43]. Nesse sentido, convém diversificar as formas de representação e uso da linguagem na Educação Infantil e oferecer condições para que as crianças produzam narrativas e expressem suas ideias, tendo o professor como escriba. 
Como as crianças utilizam tecnologias digitais com bastante desenvoltura, especialmente os dispositivos móveis, faz-se necessário inseri-los nas práticas pedagógicas vivenciadas na Educação Infantil, a fim de oferecer múltiplas linguagens e diferentes recursos para que as crianças aprendam e se desenvolvam, inseridas no mundo letrado e tecnológico.

A partir de reflexões acerca das possibilidades de produção de histórias com suporte digital na Educação Infantil, surgiu a seguinte questão: de que forma o uso de recursos digitais pode favorecer a produção textual de crianças da Educação Infantil? Tais questionamentos suscitaram a investigação dessa temática com os seguintes objetivos: acompanhar a produção textual com uso de um recurso digital na Educação Infantil e verificar se/como a utilização de um recurso digital favorece a produção de histórias na Educação Infantil.

A literatura acerca da produção textual com suporte digital da Educação Infantil é limitada e, comumente, não são encontrados registros correlatos das atividades apresentadas neste trabalho. A despeito de a produção textual e o uso de recursos digitais serem recomendados nas práticas pedagógicas desenvolvidas na Educação Infantil, ainda há uma lacuna na produção de recursos digitais e em trabalhos de pesquisa acerca dessa temática. Tanto que o recurso digital utilizado nesta investigação é recomendado para crianças a partir do $1^{\circ}$ do ano do Ensino Fundamental, conforme consta no Guia do Professor, que acompanha o referido recurso.

Bergamasco e Bergamasco (2013) apresentaram um panorama sobre a implantação de tecnologias digitais na Educação Infantil em São Paulo e pontuaram mais desafios do que avanços. Alguns desafios em relação às práticas pedagógicas com suporte digital na Educação Infantil, segundo as autoras, dizem respeito sobretudo à inexistência de políticas públicas e à falta de formação docente, a despeito de os dados apontarem para o reconhecimento docente sobre as possibilidades de aprendizagem com uso de recursos digitais.

Pesquisa apresentada por Oliveira (2009) sobre a criação de histórias com o suporte do software Teatro no Computador retrata a importância desse recurso para o desenvolvimento de habilidades como criatividade, imaginação, interpretação crítica, concentração e expressão, aspectos que também devem ser explorados em turmas de Educação Infantil. Essa pesquisa foi realizada com crianças do Ensino Fundamental, mas reforça a importância desse tipo de atividade desde a infância.

Sobreira, Nunes e Morassi (2013) utilizaram recursos tecnológicos com crianças do Ensino Fundamental para a construção de uma história não linear, a fim de promover a reconstrução de narrativas, oferecendo novas hipóteses, conforme o desenrolar do enredo, buscando oferecer maior interatividade com o leitor. Nesse trabalho, a perspectiva de estimular a produção textual também está presente, contudo o trabalho foi realizado com crianças maiores, portanto do Ensino Fundamental.

Alguns trabalhos voltados para a Educação Infantil estão mais diretamente ligados à formação de professores, como as experiências descritas por Blasques et al (2007) e Machado et al (2016), que trabalharam a leitura e a produção textual na formação de professores do Ensino Fundamental e da Educação Infantil, respectivamente. Esses trabalhos evidenciam preocupação com a produção textual das crianças, pois oferecem formação aos professores para que desenvolvam práticas pedagógicas nessa perspectiva. 
O formato deste trabalho contempla quatro partes, quais sejam: esta introdução, que discute sucintamente a fundamentação teórica, o problema e os objetivos da pesquisa; a metodologia desenvolvida; os resultados obtidos e a discussão dos achados da pesquisa; as conclusões acerca do processo vivenciado.

No próximo tópico, serão apresentados os métodos utilizados durante o desenvolvimento do trabalho.

\section{Métodos}

O paradigma interpretativo enfatiza o sentido que as coisas têm dentro de um determinado contexto, razão pela qual foi adotado neste trabalho para abarcar a natureza da percepção infantil sobre o entorno e as ações vivenciadas, já que "as ações podem ser melhor compreendidas quando são observadas no seu ambiente habitual de ocorrência" [Bogdan e Biklen 1994, p. 48].

A abordagem qualitativa de caráter interpretativo foi escolhida para dar suporte a esta pesquisa, porque permite ao pesquisador organizar os dados coletados durante a realização das atividades propostas, identificar padrões de comportamento passíveis de serem transformados em categorias de análise, delimitar as características de cada categoria e interpretar o que os dados revelam [Bogdan e Biklen 1994, p. 48].

A observação participante permitiu a coleta de dados por meio do Diário de Campo, dos registros das falas das crianças e da percepção das escolhas que faziam durante a produção de suas histórias.

O locus da pesquisa foi uma escola pública de Educação Infantil. Este trabalho foi realizado com 18 (dezoito) crianças de cinco anos de idade no ano letivo de 2015 e com treze (13) crianças também de cinco anos de idade no ano letivo de 2016.

Nessa instituição, comumente as crianças produzem narrativas, bilhetes, convites, além de ter acesso a vários gêneros textuais impressos. Assim, a utilização de um recurso digital para a produção de histórias foi uma forma de lhes oferecer diferentes meios capazes de enriquecer suas experiências e favorecer a produção textual.

As crianças eram convidadas a criar histórias, individualmente, tendo como suporte a mediação docente e o Objeto de Aprendizagem (OA) Histórias Fantásticas, desenvolvido pelo Grupo de Pesquisa e Produção de Ambientes Interativos e Objetos de Aprendizagem (PROATIVA), da Universidade Federal do Ceará (UFC).

O referido recurso digital, disponível no endereço eletrônico http://www.proativa.vdl.ufc.br/oa/historias, adequa-se a crianças dos primeiros anos do Ensino Fundamental, que já leem e escrevem convencionalmente, conforme consta no material didático disponibilizado aos usuários. Contudo, pelo fato de permitir a produção de textos e como há uma lacuna em relação à existência desse tipo de recurso para a Educação Infantil, a ideia foi experimentar se esse OA favoreceria a produção textual de crianças de cinco anos.

Assim, foi utilizada a Atividade 1, dentre as duas propostas existentes no referido OA, como pode ser observado na Figura 1. As crianças eram convidadas a criar histórias, escolhiam um dentre seis cenários possíveis para, então, selecionar as personagens, os animais e os objetos que fariam parte do cenário. 
VI Congresso Brasileiro de Informática na Educação (CBIE 2017)

Anais do XXIII Workshop de Informática na Escola (WIE 2017)

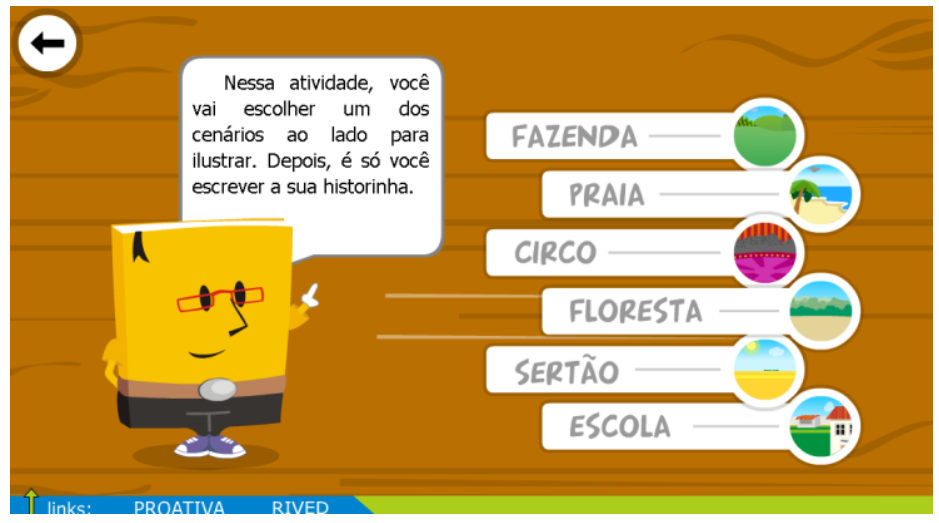

Figura 1. Tela para escolha dos cenários

Após a escolha do cenário, a criança escolhia a(s) personagem(ns), o(s) animal(is) e o(s) objeto(s) (Figura 2). Após a montagem do cenário, era feita a produção da história. Cada criança era auxiliada por um dos pesquisadores, que lia para a criança as palavras e/ou frases contidas nesse recurso digital.

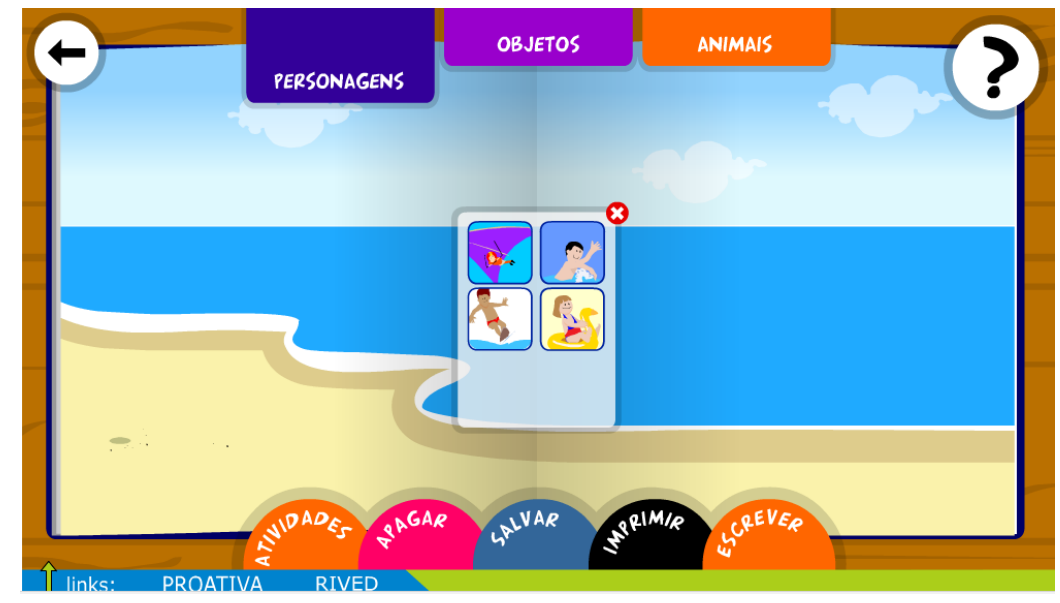

Figura 2. Tela do cenário Praia

A produção do texto era livre, mas os pesquisadores perguntavam às crianças o que estava acontecendo naquela cena, como seria(m) o(s) nome(s) da(s) personagem(ns), liam repetidas vezes o texto já produzido para que as crianças tivessem ideia de como estava construída a narrativa e, somente ao final da produção do texto, perguntavam às crianças como seria o título (ou "nome") da história que elas haviam criado.

A Figura 3 permite a visualização de uma história criada no cenário Praia. A criança colocou-se como narradora e ambientou seu relato em uma praia que visitava com frequência. Em sua narrativa, os elementos do cotidiano, da vida real misturam-se à fantasia. 


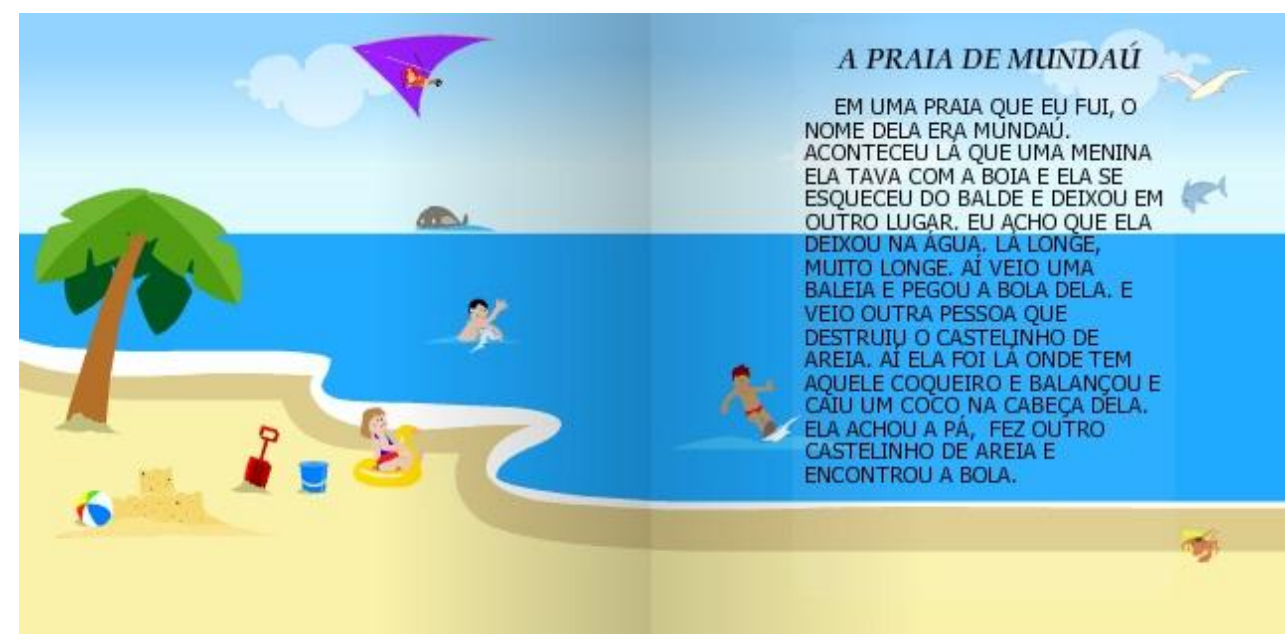

Figura 3. História criada no cenário Praia

A atribuição de título a uma narrativa é algo que requer grande capacidade de síntese e pode se tornar uma atividade complexa para crianças pequenas. Por isso, só depois que o texto havia sido produzido, os pesquisadores indagavam se as crianças queriam colocar um título ou "nome" em sua história.

Após a produção das histórias, foram organizados dois livros digitais intitulados Histórias Fantásticas 1 e Histórias Fantásticas 2, nos anos 2015 e 2016, respectivamente. A publicação online foi divulgada para a comunidade escolar, a fim de valorizar a produção textual das crianças perante os integrantes da instituição e os familiares e, ao mesmo tempo, incentivar a cultura digital no âmbito da unidade escolar.

Os referidos livros digitais encontram-se nos endereços eletrônicos http://pt.calameo.com/read/0044587816c4f5b294198 (Histórias Fantásticas - volume 1) e http://pt.calameo.com/read/00445878130462bfd7abd (Histórias Fantásticas - volume 2) e podem ser acessadas com facilidade.

\section{Resultados e discussão}

A realização dessa atividade na Educação Infantil revelou que as trinta e uma (31) crianças envolvidas neste trabalho demonstraram grande facilidade de usar $o$ computador e o OA Histórias Fantásticas, o que comprovam pesquisas de Sancho (2006), Prensky (2001) e Kenski (2007), dentre outros, acerca da facilidade com que crianças e jovens acessam os recursos digitais presentes em seu cotidiano.

O OA Histórias Fantásticas permitiu a autoria e a criatividade, pois as crianças escolhiam o cenário, as personagens, os objetos e os animais que desejavam incluir em suas histórias e, a partir de então, produziam-nas com base no cenário que haviam criado. A visualização do cenário facilitou a fluência de ideias, a criação do enredo e ratificou a ideia de que as crianças gostam de ouvir, (re)contar e criar suas próprias histórias, mesmo sem saberem ler nem escrever convencionalmente [Girão e Brandão 2011].

O cenário Praia foi escolhido por dezessete (17) crianças; o segundo cenário mais escolhido foi Circo, selecionado por cinco (5) crianças; em terceiro lugar, os cenários Floresta e Escola, ambos escolhidos por três (3) crianças; em quarto lugar, o cenário Fazenda, utilizado por duas (2) crianças; e, finalmente, o cenário Sertão, usado por uma (1) criança. Mesmo com essa diferença na escolha dos cenários, todos eles 
VI Congresso Brasileiro de Informática na Educação (CBIE 2017)

Anais do XXIII Workshop de Informática na Escola (WIE 2017)

foram selecionados pelas crianças ao longo deste trabalho.

$\mathrm{O}$ fato de as crianças residirem em uma cidade litorânea deve ter favorecido a escolha do cenário Praia, mediante a relação entre o cotidiano e a fantasia, entre a realidade e os devaneios. A possibilidade de vivenciar experiências de criação e narração de histórias, bem como a aproximação entre as linguagens oral e escrita [Brasil 2010 p. 25], certamente ampliou as aprendizagens infantis, além de encorajar as crianças para a livre expressão e a produção textual desde a Educação Infantil.

Todas as crianças produziram textos, umas com um enredo mais longo, enquanto outras fizeram narrativas mais curtas. Cinco delas necessitaram de mais espaço do que a quantidade de caracteres oferecida na página destinada à produção textual do OA utilizado. Esses dados revelam que as crianças apresentam diferentes habilidades, algumas das quais já sendo reveladas nessa faixa etária, como a capacidade de expressão, a criatividade e a eloquência, que podem ser incentivadas, trabalhadas e aperfeiçoadas ao longo da escolaridade [Brasil 1998].

O fato de cinco crianças necessitarem de mais espaço do que a quantidade de caracteres disponível no recurso digital chamou a atenção para a perspectiva de seu aperfeiçoamento, pois é possível que outras crianças, tanto da Educação Infantil como do Ensino Fundamental também necessitem de mais espaço para sua produção textual. A ampliação da quantidade de caracteres para a produção de textos favorecerá a capacidade criativa das crianças.

Em relação às personagens, duas crianças colocaram-se como protagonistas, uma delas no cenário Escola e a outra, no cenário Praia. Nos demais textos, elas se colocaram como narradoras e relataram os acontecimentos que visualizavam e/ou criavam a partir dos cenários que haviam montado.

A criação do título da história, algo que requer grande capacidade de síntese para crianças dessa faixa etária, foi realizada por vinte e nove (29) crianças. Apenas duas (2) não o fizeram, a despeito das várias tentativas feitas pelos pesquisadores. Além de ser uma atividade complexa para crianças de cinco anos, elas ficaram tão envolvidas com a narrativa, que não acharam necessário atribuir títulos às histórias, mesmo reconhecendo que toda história tem um nome.

Além desses aspectos, a utilização do OA Histórias Fantásticas tornou a produção textual uma atividade divertida porque as crianças usaram o computador e um recurso digital interativo, colorido e de fácil navegação. A existência de pequenos textos que tinham por finalidade orientar a execução da atividade foi contornada com a mediação dos pesquisadores, que procuraram tornar o momento da produção textual alegre e convidativo para que as crianças se sentissem livres e pudessem criar seus textos.

\section{Conclusões}

Os resultados obtidos permitem concluir que as crianças conseguem produzir textos desde a Educação Infantil, razão pela qual a produção de textos deve ser estimulada já nessa etapa da Educação Básica.

As crianças necessitam de um escriba/digitador, pois ainda não leem nem escrevem convencionalmente. Todavia, esse fato não inviabiliza nem dificulta a criação de histórias pelas crianças, desde que o mediador as incentive a realizar as etapas de 
VI Congresso Brasileiro de Informática na Educação (CBIE 2017)

Anais do XXIII Workshop de Informática na Escola (WIE 2017)

escolha do cenário, das personagens, dos animais, objetos e releia periodicamente o texto já produzido, para que a criança tenha condições de acrescentar ou retirar elementos e aperfeiçoar seu texto.

O suporte digital favorece a produção textual porque os elementos necessários à produção de um cenário estão disponíveis e podem ser visualizados constantemente pela criança. Além disso, o recurso digital utilizado é de simples manuseio, tem uma interface bastante amigável e favorece a aprendizagem lúdica, como devem ser as atividades na Educação Infantil.

O OA Histórias Fantásticas pode ser utilizado online ou offline, o que facilita o trabalho de professores e pesquisadores, especialmente nas instituições que têm dificuldade de acesso à Internet.

A divulgação por meio do livro digital teve muito alcance, foi bem aceita pela comunidade escolar e não gerou custos à instituição. As crianças e seus familiares sentiram-se valorizados devido à publicação do livro digital e à repercussão positiva que esse trabalho obteve em seu grupo de familiares e amigos, bem como na unidade escolar.

Diante desses aspectos, constata-se que a utilização do OA Histórias Fantásticas favoreceu a produção textual na Educação Infantil e o contato das crianças com os recursos digitais. A despeito de ter sido criado para crianças de mais idade, o referido OA pode ser utilizado sem dificuldade por crianças de cinco anos, pois favorece a ludicidade, a criatividade e a aprendizagem.

\section{Referências}

Almeida, M. Elizabeth de. (2000) "Informática e formação de professores". Vol. 1. Brasília, Ministério da Educação, Secretaria de Educação a Distância.

Bergamasco, E. C.; Bergamasco, L. C. C. (2013) "A utilização das Tecnologias de Informação e Comunicação na Educação Infantil: avanços e desafios". In: II Congresso Brasileiro de Informática na Educação (CBIE 2013) XIX Workshop de Informática na Escola (WIE 2013), UNICAMP, Campinas, São Paulo.

Blasques, Andréa et al. (2007). "Experiência Docente: Ler e Escrever? Com o Computador!" In: Anais do XXVII Congresso da SBC, XIII Workshop de Informática na Escola, Rio de Janeiro.

Bogdan, R; Biklen, S. K. (1994) "Investigação Qualitativa em Educação". Porto, Editora Porto.

Brasil. (1998) "Referencial Curricular Nacional para a Educação Infantil". Ministério da Educação e do Desporto, Brasília, 1998.

(2009) "Indicadores de Qualidade na Educação Infantil". Ministério da Educação/Secretaria da Educação Básica, Brasília, 2009.

(2009) "Resolução no 5, de dezembro de 2009", que fixa as Diretrizes

Curriculares Nacionais para a Educação Infantil.

. (2010) "Diretrizes Curriculares Nacionais para a Educação Infantil". Ministério

da Educação. Secretaria de Educação Básica. Secretaria de Educação Básica Brasília: MEC, SEB. 
VI Congresso Brasileiro de Informática na Educação (CBIE 2017)

Anais do XXIII Workshop de Informática na Escola (WIE 2017)

Girão, F. M. P. e Brandão, A. C. P. (2011). Ditando e escrevendo: a produção de textos na Educação Infantil. In: Brandão, A. C. P. e Rosa, E. C. S. "Ler e escrever na Educação Infantil" (Org.). Belo Horizonte, Autêntica Editora, 2ed.

Kenski, V. M. (2007) "Educação e tecnologias: o novo ritmo da informação". Campinas, São Paulo, Papirus.

Machado, E. M. et al. (2016). "A formação do leitor e escritor na perspectiva da inclusão digital de crianças". In: V Congresso Brasileiro de Informática na Educação (CBIE 2016), Anais do XXII Workshop de Informática na Escola (WIE 2016), Uberlândia, Minas Gerais.

Oliveira, Celina Couto et al (2001). "Ambientes informatizados de aprendizagem: produção e avaliação de software educativo". Campinas, São Paulo, Papirus.

Oliveira, Osvaldo Luiz. (2009) "Criando e Recriando Histórias". In: XX Simpósio Brasileiro de Informática na Educação. UFSC/UNIVALI, Florianópolis, Santa Catarina.

Papert, Seymour. (2008) "A máquina das crianças: repensando a escola na era da informática". Porto Alegre, Artmed.

Prensky, Marc. (2001) Digital Natives, Digital Immigrants - Part 1. In: Digital Natives, Digital Immigrants. MCB University Press, Vol. 9, No. 5.

Sancho, J.M. (Org.). (2006) "Tecnologias para transformar a educação". Porto Alegre, Artmed.

Sobreira, E. S. R.; Nunes, M.C.; Morassi, S. B. (2013) "Produzindo histórias não lineares: um incentivo à produção escrita e leitura, através do uso contextualizado da tecnologia". In: II Congresso Brasileiro de Informática na Educação (CBIE 2013) XIX Workshop de Informática na Escola (WIE 2013), UNICAMP, Campinas, São Paulo.

Valente, J. A. (1993) Formação de Profissionais na Área de Informática em Educação. In: Valente, J.A (Org.) "Computadores e Conhecimento: repensando a educação". Campinas, Gráfica da UNICAMP. 